\title{
DESAFIOS E PERSPECTIVAS DA PRODUÇÃO DE AREIA INDUSTRIAL
}

\author{
M. S. Ruiz ${ }^{1}$, M. Cabral Júnior ${ }^{2}$, L. C. Tanno ${ }^{2}$, J. M. Coelho ${ }^{3}$ e P. L. Cortês ${ }^{1}$ \\ ${ }^{1}$ Universidade Nove de Julho - Uninove \\ ${ }^{2}$ Instituto de Pesquisas Tecnológicas - IPT \\ ${ }^{3}$ Universidade Federal do Rio de Janeiro \\ E-mail: maurosilvaruiz@gmail.com ${ }^{1}$
}

Artigo submetido em outubro/2013 e aceito em novembro/2013

\section{RESUMO}

A areia industrial é utilizada como matéria-prima nas indústrias de vidro, fundição, química, cerâmica, tintas, plásticos, entre outras. As reservas brasileiras mais expressivas estão localizadas nos estados de São Paulo e Minas Gerais. Os maiores depósitos e minas em operação no Estado de São Paulo estão nos municípios Analândia e Descalvado. O objetivo deste trabalho é caracterizar o segmento de areia industrial em todo o país enfatizando a distribuição espacial das reservas, o nível de produção e as instalações existentes, e os desafios tecnológicos e ambientais relacionados à lavra e ao beneficiamento. Também inclui estimativas para a produção deste bem mineral no período de 2012 a 2030 e compara com as reservas existentes. O desejo de conhecer os principais desafios e perspectivas da produção de areia industrial no Brasil norteou a pesquisa deste artigo

PALAVRAS-CHAVE: areia industrial, aspectos tecnológicos, problemas ambientais

\section{CHALLENGES AND PERSPECTIVES OF THE INDUSTRIAL SAND PRODUCTION}

\begin{abstract}
Industrial sand is used as raw materials in glass industries, foundry, ceramic, chemical, paint, plastics and many others. The Brazilian largest reserves are located in the states of Sao Paulo and Minas Gerais. The largest deposits and operating mines in Sao Paulo State are located in the Analandia and Descalvado municipalities. The aim of this paper is to characterize the segment of industrial sand countrywide emphasizing the spatial distribution of reserves, the level of
\end{abstract}

production and production facilities, and both the technological and environmental challenges related to sand mining and processing. It also includes estimates for the industrial sand production from 2012 to 2030 and compares to the existing reserves. The desire to know the main challenges and prospects of industrial sand production in Brazil has guided the research presented in this article.

KEYWORDS: Industrial sand, technological aspects, environmental problems. 


\section{DESAFIOS E PERSPECTIVAS DA PRODUÇÃO DE AREIA INDUSTRIAL}

\section{INTRODUÇÃO}

O termo areia industrial geralmente é utilizado para designar areias silicosas empregadas, em estado natural ou beneficiadas, na fabricação de vidro e moldes para fundição, que constituem suas aplicações mais importantes; bem como em produtos cerâmicos e cimento, como carga mineral em tintas e plásticos, na fabricação de ácidos e fertilizantes na indústria química, dentre outros processos e produtos. Trata-se de um conceito bastante amplo e compreende areias com elevado conteúdo de quartzo, com uma multiplicidade de aplicações, cada uma com especificação granulométrica e química bem definida.

No Brasil, a produção de areia industrial ocorre essencialmente segundo coberturas sedimentares arenosas friáveis, com uma contribuição subordinada de outras variedades de substâncias minerais como quartzitos e silexitos (rochas metamórficas e magmáticas) que, a depender do tipo de aplicação, necessitam de moagem para a adequação granulométrica.

A importância de seu estudo, tanto do ponto de vista estritamente técnico quanto da gestão de materiais e recursos minerais, relaciona-se à sua ampla utilização na construção civil, indústria vidreira, engenharia de materiais e metalurgia. Desde o início deste século, acompanhando o crescimento da economia brasileira, os principais segmentos consumidores de areia industrial impulsionam a expansão e a descentralização da sua indústria extrativa. Por sua vez, a sua obtenção, com base em fontes naturais, pode causar impactos ambientais relevantes e que devem ser considerados e devidamente mitigados, ampliando a importância de seu estudo. $\mathrm{Na}$ literatura nacional e internacional também se verifica um interesse crescente pela publicação de artigos que abordam o aproveitamento desse bem mineral, conforme comentado nesta revisão.

Ao considerar a sua demanda crescente, os impactos gerados pela exploração e as alternativas existentes para sua obtenção, uma indagação que se manifesta é: "Quais os principais desafios e perspectivas da produção de areia industrial no Brasil", que se constitui na questão de pesquisa que norteou o desenvolvimento deste trabalho. Com a resposta a essa indagação, levou-se em consideração as seguintes premissas:

- caracterizar o segmento de areia industrial no país no que se refere à distribuição espacial das reservas, da produção e do parque produtivo;

- verificar os principais aspectos e desafios tecnológicos da lavra e beneficiamento;

- analisar os problemas ambientais relacionados à produção deste bem mineral.

O presente artigo resultou da complementação e atualização de informações utilizadas na confecção do relatório técnico sobre areia industrial (Coelho, 2010), utilizado na elaboração do Plano Duodecenal (2008 - 2028) de Geologia, Mineração e Transformação Mineral. A estratégia metodológica para o desenvolvimento da pesquisa comprendeu a revisão da literatura sobre o tema, o levantamento de informações no Departamento Nacional da Produção Mineral (DNPM), realização de entrevistas com representantes de grupos mineradores, e estimativas de produção até 2030 . Além de comparar as produções estimadas com as reservas existentes no país, buscouse também estabelecer um entendimento inicial sobre os desafios tecnológicos e ambientais da produção deste bem mineral no Brasil.

\section{REVISÃo BIBLIOGRÁFICA}


Verifica-se uma ampla diversidade de enfoque nas publicações nacionais e internacionais sobre areia industrial. Enquanto alguns analisam as reservas geológicas e aspectos inerentes à sua mineração, outros discorrem sobre sua utilização em processos industriais os mais variados. Em decorrência desse cenário diversificado, a revisão bibliográfica foi dividida nos tópicos:

- 'panorama geral', no qual se discorre sobre a produção científica sobre o tema; e

- 'produção', no qual se discute os seus principais mercados e aplicações.

Esses tópicos são anunciados a seguir:

\subsection{Panorama geral}

A areia industrial começou a receber atenção na literatura técnica nacional nos últimos 30 anos, pois até então os estudos sobre mineração e matérias-primas estavam mais direcionados à produção de minérios metálicos de alto valor no mercado internacional e bens minerais destinados, principalmente, à produção de insumos agrícolas. Levantamento efetuado na base Web of Science, para o período de 1980 a 2012, indicou 191 trabalhos publicados que abordam o tema sand exploitation ou sand mining, conforme ilustrado na Figura 1. É possível verificar que desde o final da década de 1990 houve um incremento das publicações sobre esses temas, demonstrando maior interesse pelo assunto.

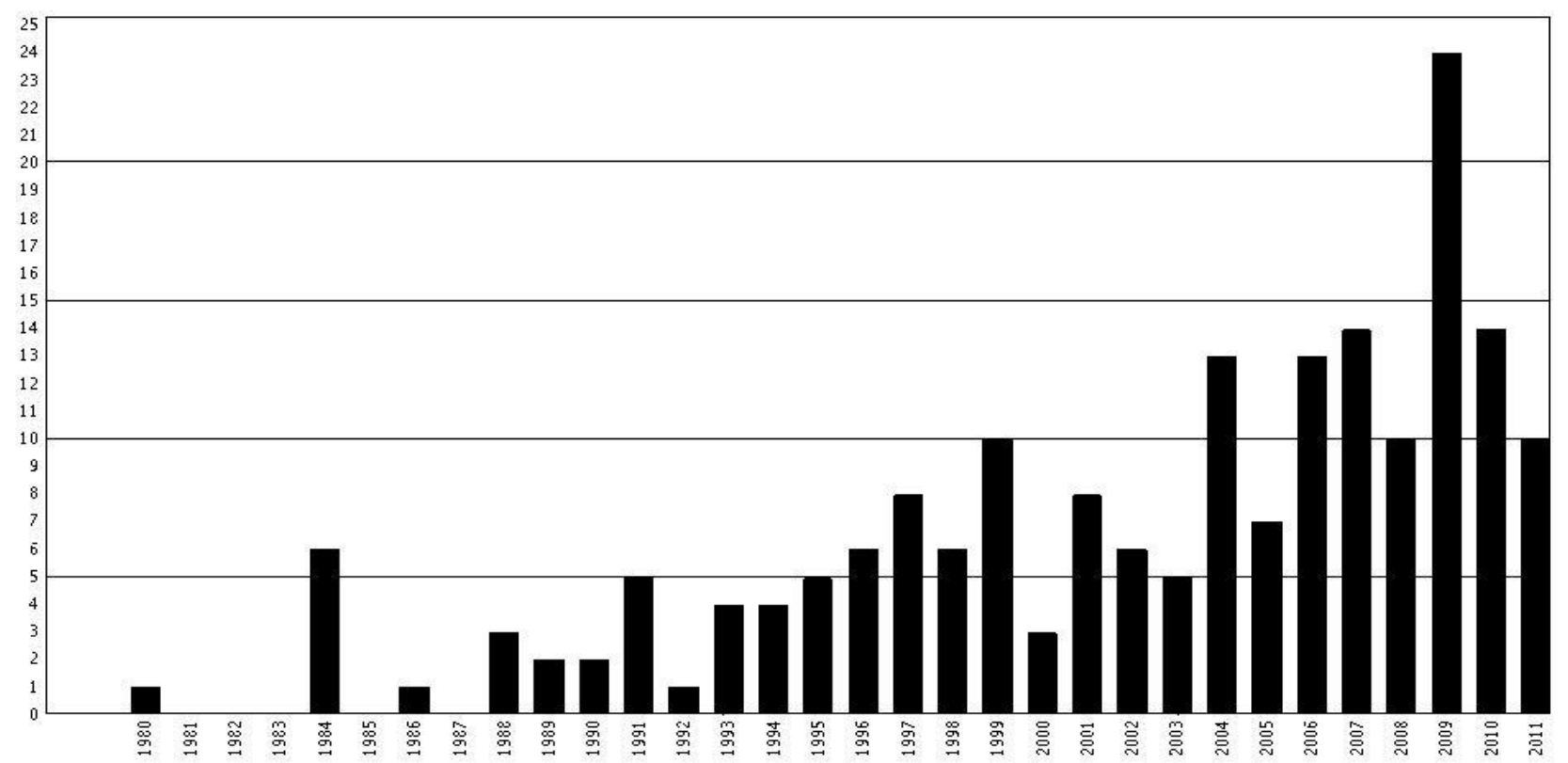

Topic=("sand exploitation") OR Topic=("sand mining")

Timespan=1980-2012. Databases=SCI-EXPANDED, SSCl, A\&HCl, CPCI-S, CPCl-SSH.

Lemmatization=On Nota: levantamento efetuado pelos autores em fevereiro de 2012.

Figura 1 - Distribuição dos 191 trabalhos disponíveis na base Web of Science e que abordam o tema sand exploitation ou sand mining no período de $1980-2012$.

Dentre os trabalhos identificados nesse levantamento, 135 são artigos publicados em revistas científicas $(70,6 \%)$ e o restante corresponde aos trabalhos apresentados em eventos científicos, revisões e avaliações de livros. Dos artigos científicos encontrados, há aqueles relacionados ao tema sand exploitation ou sand mining de maneira mais direta, enquanto outros abordam esses tópicos apenas de maneira acessória. Entre os artigos verificados, há uma concentração de trabalhos sobre mineração de areia em ambientes marinhos e os impactos 
ambientais decorrentes (HOBBS, 2007; DIAZ, CUTTER e HOBBS, 2004; HOBBS, 2002; MAA et al., 2004; MAA, HOBBS e HARDAWAY JR, 2001), mas há que se considerar que a prática da mineração na região marinha não é usual no País, sobretudo, em decorrência da elevada dotação mineral das áreas de plataformas continentais.

Os estudos nacionais realizados nessa época têm um enfoque variado: Dias (1981), por exemplo, discutiu as especificações de uso para vários fins industriais, enquanto Nava (1986) dedicou-se a estudos geológicos na região de Descalvado. Azevedo e Ruiz (1990) elaboraram um perfil do setor enfocando os aspectos produtivos da lavra e beneficiamento, a organização industrial das empresas mineradoras e as principais questões mercadológicas. Ainda na década de 1990, há os trabalhos de Ferreira (1997) e Ferreira e Daitx (1997), abordando a mineração de areia industrial e analisam, principalmente, os mercados produtores no estado de São Paulo.

Desde o ano 2000 os estudos sobre areias industriais foram intensificados, situação essa também verificada no levantamento realizado no Web of Science, conforme já mencionado. Dessa época é possível destacar os trabalhos de Ferreira e Daitx (2003a; 2003b), que analisaram os mercados de São Paulo, Santa Catarina, Paraná e Rio Grande do Sul, e Luz e Linz (2005) e Ferreira e Daitx (2000), analisando seu uso em indústrias químicas, cerâmica e de tintas. Chaves e Whitaker (2010), por sua vez, detalharam os aspectos técnicos das operações de beneficiamento de areia com foco na orientação às pequenas e médias empresas mineradoras que são maioria no setor.

\subsection{Produção}

Luz e Lins (2005) e o British Geological Survey (2004) destacam que, em função das propriedades físicas e químicas, as areias industriais são mais valorizadas no mercado, comparativamente, às areias utilizadas diretamente na construção civil. Teor de sílica, pureza, composição química, teor de óxidos de ferro, álcalis, matéria orgânica, perda ao fogo, umidade, distribuição granulométrica, forma dos grãos e teor de argila são características importantes e expressam propriedades determinantes das diferentes aplicações industriais dessas areias (AZEVEDO; RUIZ, 1990; LUZ; LINS, 2005). Os teores de $\mathrm{SiO}_{2}, \mathrm{Fe}_{2} \mathrm{O}_{3}, \mathrm{Al}_{2} \mathrm{O}_{3}, \mathrm{MnO}_{2}, \mathrm{MgO}, \mathrm{CaO}, \mathrm{TiO}_{2} \mathrm{e}$ $\mathrm{ZrO}_{2}$ definem as principais especificações técnicas de natureza química para os diferentes usos. Os teores de $\mathrm{Cr}_{2} \mathrm{O}_{3}, \mathrm{Na}_{2} \mathrm{O}$ e $\mathrm{K}_{2} \mathrm{O}$ também são considerados quando se trata de usos específicos (LUZ; LINZ, 2005; FERREIRA; DAITX, 2000), principalmente nas indústrias químicas, cerâmica e de tintas.

As estatísticas disponíveis sobre produção mundial de areia industrial encontram-se defasadas no tempo. Segundo estimativas do U. S. Geological Survey (2009), a produção mundial é de aproximadamente $120 \mathrm{Mt} / \mathrm{ano}$. A título de comparação com o Brasil, a produção dos EUA em 2006 alcançou 31,9 Mt, correspondendo a um valor de US\$ 800 milhões (U. S. GEOLOGICAL SURVEY, 2009), com consumo aparente de $29,7 \mathrm{Mt}$, enquanto a produção brasileira beneficiada em 2006 foi de aproximadamente 4,9 Mt e o valor desta produção foi de US\$ 68,3 milhões. As estatísticas brasileiras para este minério também se encontram bastante defasadas em função do atraso de três anos pelo DNPM na publicação do Anuário Mineral Brasileiro.

A produção de areias especiais, geralmente empregadas nas indústrias do petróleo (auxiliar na fluidez do óleo bruto das fraturas), cerâmica, química, e na fabricação de tintas, demandam processamento diferenciado para remoção de impurezas que podem ser constituídas por minerais pesados como zircão, ilmenita, magnetita, cromita ou substâncias que tenham aderido à superfície dos grãos de quartzo. A purificação por flotação ou por métodos gravíticos 
pode ser empregada. A flotação em meio ácido é usada em duas usinas na Inglaterra, para remover minerais pesados. A lixiviação a quente, com ácido sulfúrico, também é praticada em três instalações naquele país, para limpar a cobertura ferrosa das partículas individuais (BRITISH GEOLOGICAL SURVEY, 2004). Essas areias especiais também podem ser recobertas com resinas aglomerantes, obtendo-se produtos de alto valor agregado. Esta areia resinada, com produção em torno de 12.000 t/ano, alcança no Brasil preços 10 a 15 vezes maiores que aqueles praticados com as areias comuns de fundição. Para uso em alguns produtos cerâmicos, a areia de sílica é calcinada para converter o quartzo em cristobalita. Tanto a cristobalita como a areia de quartzo são finamente moídas para a obtenção de sílica flúor de várias especificações (BRITISH GEOLOGICAL SURVEY, 2004).

Ferreira e Daitx (2003a), ao analisarem os mercados produtores no sul do país, citam que a maior produção concentra-se em Santa Catarina, nos municípios de Araguari, Jaguaruna e Imbituba, com cerca de $80 \%$ de toda areia industrial produzida naquela região, com $75 \%$ desta produção destinada às indústrias de fundição na região de Joinville. As minerações existentes no Paraná (municípios de Campo Largo e Lapa) e no Rio Grande do Sul (município de Viamão) abastecem principalmente as indústrias cerâmicas e de vidro da própria região.

Nos principais municípios produtores predomina a integração da mina com a unidade de beneficiamento. Shreve e Brink Junior (1977) constataram que sendo a areia quartzosa a principal matéria-prima na manufatura do vidro, a localização das jazidas de areia, em muitos casos, influenciava na localização das fábricas. Contudo, mais recentemente, outros fatores passaram a ter um peso mais preponderante na localização dessas fábricas, caso da logística e a disponibilidade de energia, em particular do gás natural.

Nas minerações em que uma parcela importante da areia é destinada à indústria vidreira, o material arenoso necessita de beneficiamento para o aumento do grau de pureza em termos de sílica. Nesses empreendimentos, tomando como princípio as frentes de lavra, as areias são transportadas para as unidades de beneficiamento, situadas ao lado das minas, onde são processadas separadamente das areias com outras destinações no mercado (FERREIRA, 1997).

A areia para argamassa também é incorporada nas estatísticas do DNPM como areia industrial, embora especialistas no assunto a considerem como areia para construção. A produção de areia para argamassa cresceu consideravelmente nas últimas décadas em função do aumento da demanda do setor de construção civil.

Em função do exposto, de um lado a forma como o DNPM agrega as suas estatísticas e, de outro, o conceito de areia industrial comumente aceito entre os especialistas, o assunto areia para argamassa é tratado de forma secundária neste trabalho.

\section{METODOLOGIA}

Segundo a revisão da literatura, foi possível avaliar as principais questões relacionadas à produção de areia industrial. Após essa análise inicial, considerou-se necessário verificar "Quais os principais desafios e perspectivas da produção de areia industrial no Brasil?" fundamento que orientou este estudo. Como resposta a essa questão, procurou-se atender as seguintes premissas: 
- caracterizar o segmento de areia industrial no país no que se refere à distribuição espacial das reservas, da produção e do parque produtivo;

- verificar os principais aspectos e desafios tecnológicos da lavra e beneficiamento;

- analisar os problemas ambientais relacionados à produção deste bem mineral.

Buscando obter uma resposta à questão de pesquisa e atender ao objetivo proposto, delineou-se uma estratégia metodológica, utilizando bibliografia específica para definir o recorte adotado (SEVERINO, 2007; APPOLINÁRIO, 2004; COOPER e SCHINDLER, 2003). Com base no entendimento inicial, propiciado pela revisão da literatura, foram sistematizadas informações secundárias disponíveis no Anuário Mineral Brasileiro do DNPM. Tanto a revisão bibliográfica quanto as informações secundárias chegou-se a um entendimento sobre produção, consumo e reservas que subsidiou a realização de entrevistas com representantes da Saint Gobain e da Mineração Descalvado (Grupo Owins Illinois do Brasil). Desta forma, foi possível elaborar um panorama sobre os setores envolvidos na produção e processamento da areia industrial no País.

Com base no panorama obtido, procedeu-se a elaboração de estimativas para a produção de areia industrial para o período entre 2010 e 2030, tomando como referência alguns cenários que foram elaborados para a economia nacional. Tais cenários consideraram como fatores a estabilidade ou instabilidade econômica, as reformas e inovação para os próximos anos e as projeções de crescimento anual do PIB para a mineração de não metálicos. Os dados da Tabela 1 correspondem ao crescimento do PIB para a mineração de não metálicos no período 1990-2008 que serviu de base para estimar alguns índices de crescimento do PIB para o setor de não metálicos para as duas próximas décadas e, assim se projeta o consumo e a produção de areia industrial para o país.

Tabela 1: Crescimento do PIB para a mineração de não metálicos no período 1990-2008

\begin{tabular}{|cc}
\hline Ano & Índice de Crescimento \\
\hline 1990 & 10,9 \\
1991 & 11,2 \\
1992 & 10,1 \\
1993 & 10,2 \\
1994 & 11,4 \\
1995 & 10,4 \\
1996 & 9,1 \\
1997 & 10,2 \\
\hline 1998 & 10,0 \\
\hline 1999 & 8,8 \\
\hline 2000 & 8,2 \\
\hline 2001 & 8,3 \\
\hline 2002 & 8,6 \\
\hline 2003 & 9,8 \\
\hline 2004 & 10,0 \\
\hline 2005 & 8,8 \\
\hline 2006 & 10,2 \\
\hline 2007 & 10,8 \\
\hline 2008 & 41,1 \\
\hline
\end{tabular}

Fonte: elaborada pelos autores

Os cenários para o futuro da mineração de areia industrial baseados em estimativas de crescimento do PIB da mineração de não metálicos, entre 2010 e 2030, foram classificados em 
frágil, vigoroso e inovador, basearam-se, respectivamente, em perspectivas de instabilidade e retrocesso; estabilidade e reformas; estabilidade, reforma e inovação para a economia nacional, atrelados à estimativas de crescimento anual do PIB da mineração de não metálicos. Para o cenário frágil adotou-se como índice de projeção do crescimento futuro, no período 2010 até 2030, o valor mínimo de índice de crescimento do PIB da Tabela 1(8,2\%). Para o cenário vigoroso adotou-se o índice de 9,1\%, e para o cenário inovador o de 10,0\%. As descrições desses cenários estão relacionadas na Tabela 2 e os índices de crescimento do PIB para a mineração de não metálicos para cada um deles foram utilizados para estimar as produções de areia industrial no período $2010-2030$.

Tabela 2: Cenários para o futuro da mineração de areia industrial baseados em estimativas de crescimento do PIB da mineração de não metálicos.

\begin{tabular}{|c|c|c|c|}
\hline Cenário & Caracterização & \multicolumn{2}{|c|}{$\begin{array}{c}\text { Projeção do Crescimento do PIB - } \\
\text { Produto Interno Bruto - Mineração de } \\
\text { não Metálicos (\% a.a.) }\end{array}$} \\
\hline 1 - Frágil & $\begin{array}{l}\text { Instabilidade e Retrocesso: } \\
\text { Considera uma possível reversão dos atuais condicionamentos } \\
\text { sócio-políticos e a desestabilização do atual contexto fiscal e } \\
\text { monetário. O país deverá regredir no processo de estabilização } \\
\text { de sua economia, concomitantemente a retrocessos no plano } \\
\text { externo, com deterioração do atual contexto de integração } \\
\text { competitiva à economia internacional. }\end{array}$ & Médio - Período 2010 a 2030 & 8,2 \\
\hline 2 - Vigoroso & $\begin{array}{l}\text { Estabilidade e Reformas: } \\
\text { Pressupõe a manutenção e o aperfeiçoamento das atuais } \\
\text { condições de estabilidade e de aprofundamento das reformas } \\
\text { político-institucionais, especialmente nos campos da gestão } \\
\text { pública (reforma administrativa), fiscal (reforma tributária), e } \\
\text { da previdência social (reforma previdenciária), além das } \\
\text { concessões de serviços de infraestrutura (saneamento, } \\
\text { energia, portos e transporte rodoviário, fluvial e marítimo). }\end{array}$ & Médio - Período 2010 a 2030 & 9,8 \\
\hline 3 - Inovador & $\begin{array}{l}\text { Estabilidade, Reformas e Inovação } \\
\text { Admite um condicionamento ainda mais virtuoso, no qual - } \\
\text { além do aperfeiçoamento da estabilização e do } \\
\text { aprofundamento das reformas institucionais - o país } \\
\text { empreende uma vigorosa mobilização nacional pela inovação, } \\
\text { contando com uma ampla participação de instituições } \\
\text { públicas, entidades não governamentais, empresas e da } \\
\text { sociedade como um todo. Admite-se que tal processo de } \\
\text { mobilização seja focado em planos e programas direcionados } \\
\text { para uma ampla geração e difusão de informação, } \\
\text { conhecimento e aprendizado, como estímulo a projetos } \\
\text { específicos de pesquisa, desenvolvimento e inovação. }\end{array}$ & Médio - Período 2010 a 2030 & 11,2 \\
\hline
\end{tabular}

Fonte: Elaborada pelos autores 


\section{ANÁLISE DOS DADOS E INFORMAÇÕES}

Este tópico atende aos objetivos de pesquisa já mencionados, caracterizando a estrutura empresarial e de mercado, e a distribuição espacial das reservas; enfatizando os principais aspectos e desafios tecnológicos da lavra e beneficiamento e ponderando as questões ambientais relacionadas à produção deste bem mineral.

\subsection{Parque produtivo e estrutura empresarial}

A produção brasileira de areia industrial adicionou um importante crescimento nos anos 2000. Partindo-se de uma produção anual de cerca de 5,0 milhões de toneladas no início da década, alcançou o seu auge em 2008, totalizando 7,0 milhões, o que correspondeu a um faturamento da ordem de $\mathrm{R} \$ 233$ milhões (Figuras 2 e 3 ).

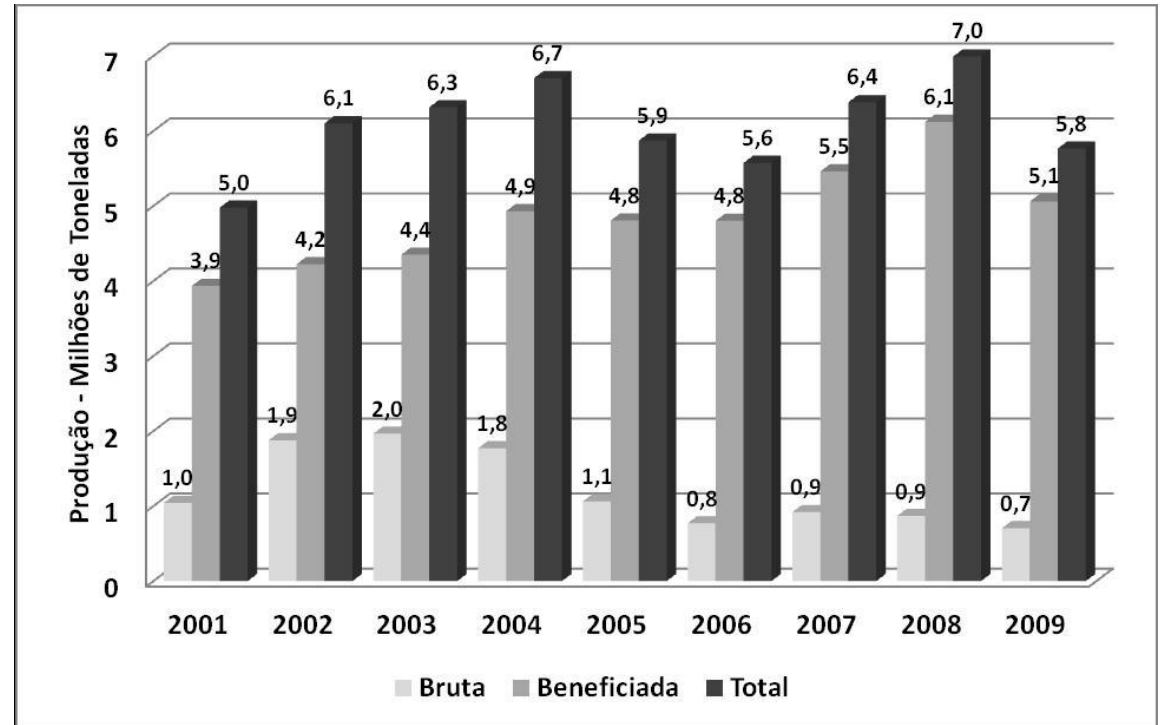

Fonte: Departamento Nacional da Produção Mineral (2002 a 2010)

Figura 2 - Produção brasileira de areia industrial - quantidade

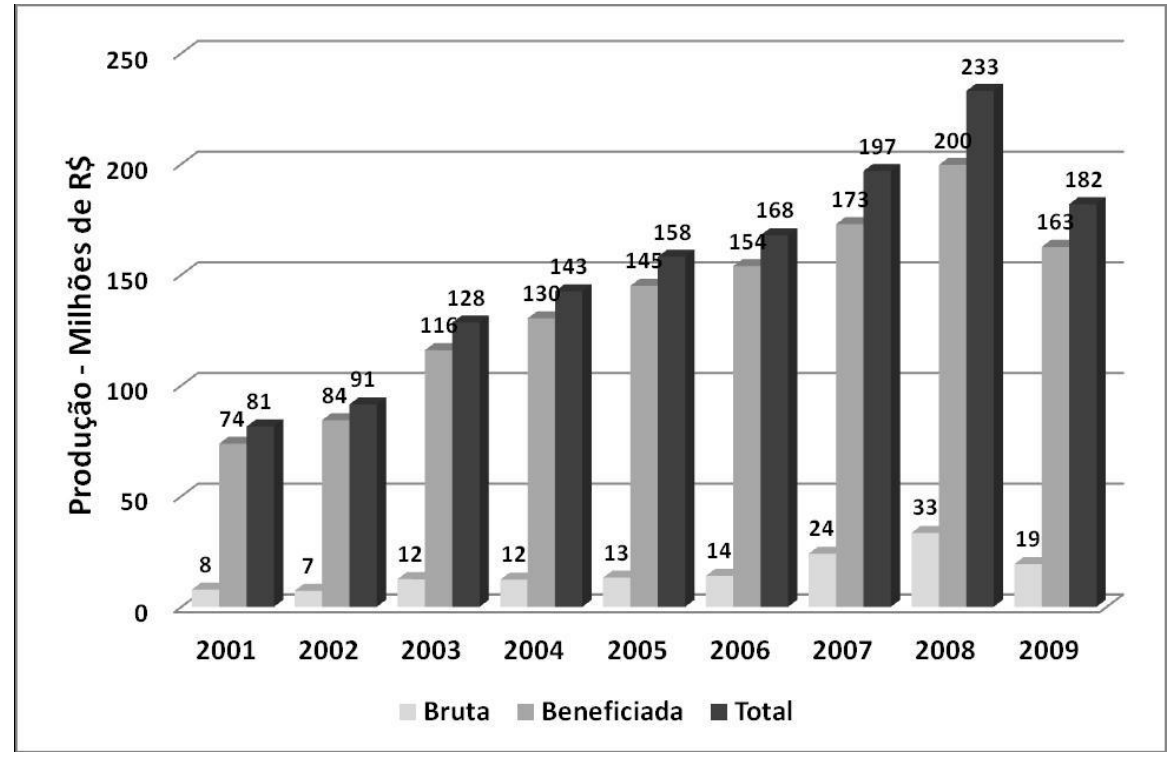

Fonte: Departamento Nacional da Produção Mineral (2002 a 2010)

Figura 3 - Produção brasileira de areia industrial - valor 
Nesse período de 2001 a 2008, em decorrência do aumento de preços da areia industrial comercializada nas formas bruta e beneficiada, a expansão da produção em quantidade foi de cerca de $30 \%$ e o crescimento em valor foi de $188 \%$, ou seja, quase triplicou. Já a queda expressiva na produção, verificada em 2009, refletiu o arrefecimento da economia brasileira, reflexo da crise internacional iniciada no final de 2008.

Apesar das informações oficiais relativas às produções e valores de produções desse bem mineral ainda não estarem disponíveis para 2010, 2011 e 2012, é provável que este cenário tenha se modificado em função da retomada do crescimento da economia brasileira, sobretudo em 2010.

Os estados de São Paulo, Santa Catarina e Minas Gerais lideram amplamente a produção nacional (Figura 4). Do total de R\$ 182 milhões produzidos em 2009, os três estados responderam por $\mathrm{R} \$ 160,5$ milhões, o que correspondeu a mais de $88 \%$ em valor da produção no País.

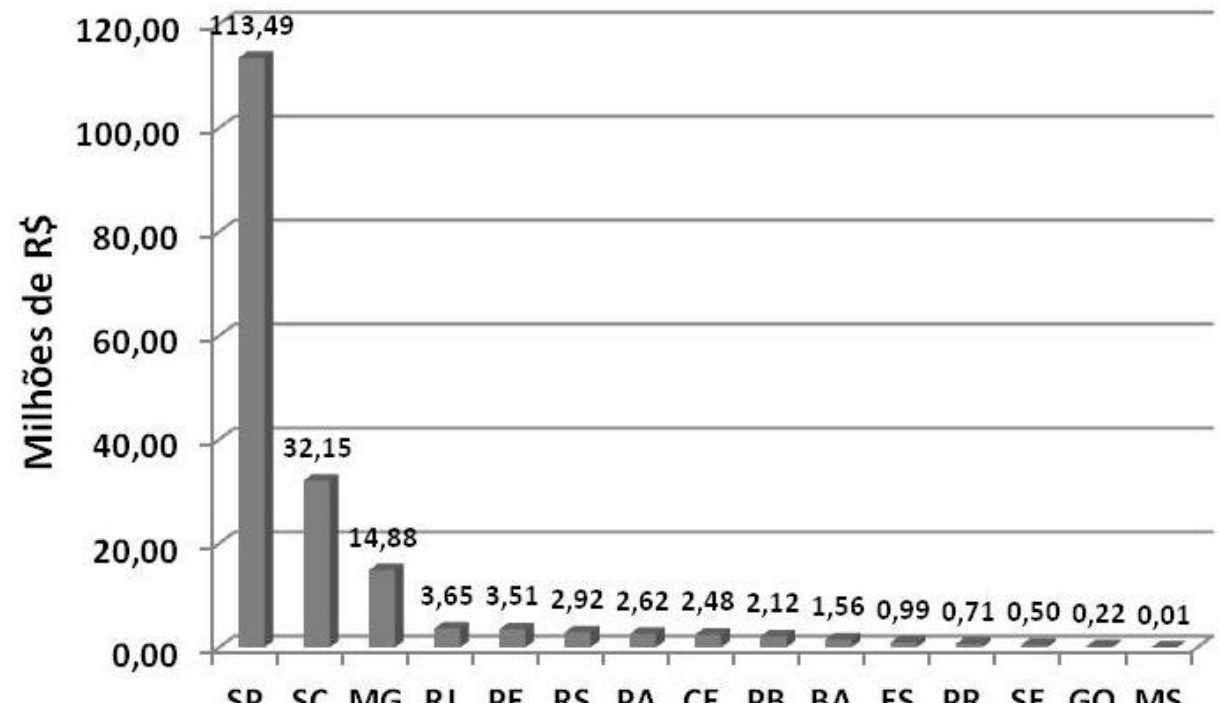

Fonte: Departamento Nacional da Produção Mineral (2010)

Figura 4 - Produção brasileira de areia industrial por unidades da Federação em 2009

Ao se seguir uma tendência internacional, à despeito de algumas dezenas de empresas participarem da produção de areia industrial, o parque produtivo no País encontra-se relativamente concentrado, sendo que as 10 maiores empresas são responsáveis por mais de $80 \%$ do montante minerado (DNPM, 2010), com mais de $65 \%$ da produção efetuada por empresas multinacionais (Tabela 3).

Tabela 3: Participação na produção nacional comercializada pelas principais empresas produtoras de areia industrial em 2009

\begin{tabular}{|lcc|}
\hline \multicolumn{1}{c}{ Empresas } & UF $^{1}$ & Participação (\%) $^{2}$ \\
\hline Mineração Jundu Ltda & MG, SC, SP & 45,23 \\
\hline Mineração Descalvado Ltda. & SP & 10,36 \\
\hline Unimin do Brasil Ltda. & SC & 5,73 \\
\hline Mineração Veiga Ltda. & SC & 4,74 \\
\hline Saint-Gobain do Brasil Ltda. & MG, SP & 4,69 \\
\hline
\end{tabular}




\begin{tabular}{|c|c|c|}
\hline Empresa Brasileira do Quartzo Ltda. & BA, MG & 2,89 \\
\hline Empresa de Mineração Elias João Jorge Ltda. & SP & 2,58 \\
\hline Votorantim Cimentos N/NE S.A. & $\mathrm{CE}, \mathrm{PB}$ & 2,45 \\
\hline Darcy R. O. e Silva \& Cia. Ltda & SP & 2,33 \\
\hline Curupi Mineração S.A. & RJ & 2,01 \\
\hline \multicolumn{3}{|c|}{$\begin{array}{l}{ }^{1} \text { Unidade da Federação onde ocorreu a comercialização e/ou consumo da produção bruta e/ou } \\
\text { beneficiada. } \\
{ }^{2} \text { Participação percentual da empresa no valor total da comercialização da substância. }\end{array}$} \\
\hline \multicolumn{3}{|c|}{ Fonte: Departamento Nacional da Produção Mineral (2010) } \\
\hline
\end{tabular}

O mercado produtor paulista evidencia claramente essa tendência de oligopólio. No início dos anos 2000, somente no estado de São Paulo havia 41 empresas produtoras de areia industrial (FERREIRA; DAITX, 1997). As informações coletadas nas pesquisas de campo (entrevistas com executivos) indicam que este número decresceu substancialmente, devendo estar operando cerca de 20 empresas em 2012.

Liderando a produção brasileira (45\%), a Mineração Jundu é detentora de minas nos estados de São Paulo (municípios de Descalvado e Analândia), Rio Grande do Sul (Viamão), Santa Catarina (Balneário Barra do Sul) e Minas Gerais (São João Del Rei). A Mineração Jundu S.A., joint venture com $50 \%$ do capital pertencente à Saint Gobain e $50 \%$ à Unimin (empresa belgoamericana), fornece areia para as indústrias de vidro, fundição, cerâmica e química.

A Saint Gobain, por meio de sua divisão Weber-Quartzolit, produz areia para argamassas em mina localizada no município de Bofete (interior de São Paulo), que abastece a sua unidade de produção de argamassa em Jandira, na Região Metropolitana de São Paulo. Outro importante player paulista, a Mineração Descalvado, empresa de porte médio, que era familiar até recentemente, quando foi incorporada pelo grupo americano Owins Illinois do Brasil.

Na região Sul existe cerca de 10 empresas relativamente bem estruturadas que produzem areias para vários fins industriais, com destaque para a fundição. A principal empresa é a Mineração Veiga (SC), responsável por aproximadamente $55 \%$ da produção regional. Ela abastece principalmente a Tupy Fundições, maior fundição da América Latina, que consome anualmente cerca de 150.000 t de areia industrial. Distribuídas nas demais mineradoras, os $45 \%$ restantes da produção sulina destinam-se a pequenas e médias fundições, indústrias cerâmicas e vidreiras, e fabricantes de argamassa (FERREIRA; DATIX, 2003a).

Nos estados do Rio de Janeiro, Espírito Santo, Mato Grosso, Bahia, Pará e Amazonas há poucos produtores qualificados de areia, porém, alguns deles vêm se estruturando, nos últimos anos, para produzirem areia de melhor qualidade para fabricação de argamassa.

Segundo Nogueira (2008), gerente regional de operações e geologia da Divisão WeberQuartzolit da Saint Gobain, esta empresa enfrenta dificuldades relacionadas ao desenvolvimento de fornecedores regionais comprometidos com qualidade do produto, prazos de entrega e manutenção de preço.

Paralelamente à expansão da produção de areias industriais ocorreu uma descentralização da mineração, comandada por áreas com demandas emergentes, caso das regiões Sul, Nordeste e Centro-Oeste (Figura 5). 


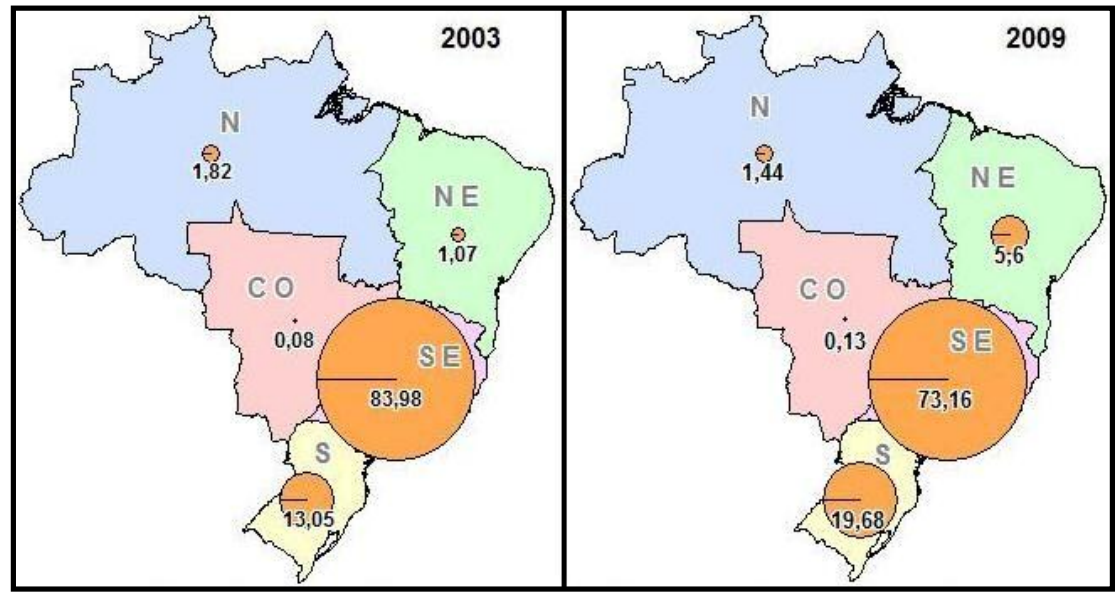

Fonte: Departamento Nacional da Produção Mineral (2004 e 2010)

Figura 5 - Evolução da produção de minerais industriais por regiões em 2003 e 2009 (\%) - em valor.

De forma agregada, a demanda por areia industrial no País é ditada principalmente pelos setores da construção civil (36\%), sobretudo pelos segmentos de argamassas, vidreiro (24\%) e fundição (24\%), que juntos perfazem $84 \%$ do seu consumo (Figura 6). Os demais $16 \%$ correspondem a um número expressivo de segmentos industriais, destacando-se pelo maior consumo as indústrias cerâmica, cimenteira, e de ferro-ligas, e o uso como material filtrante.

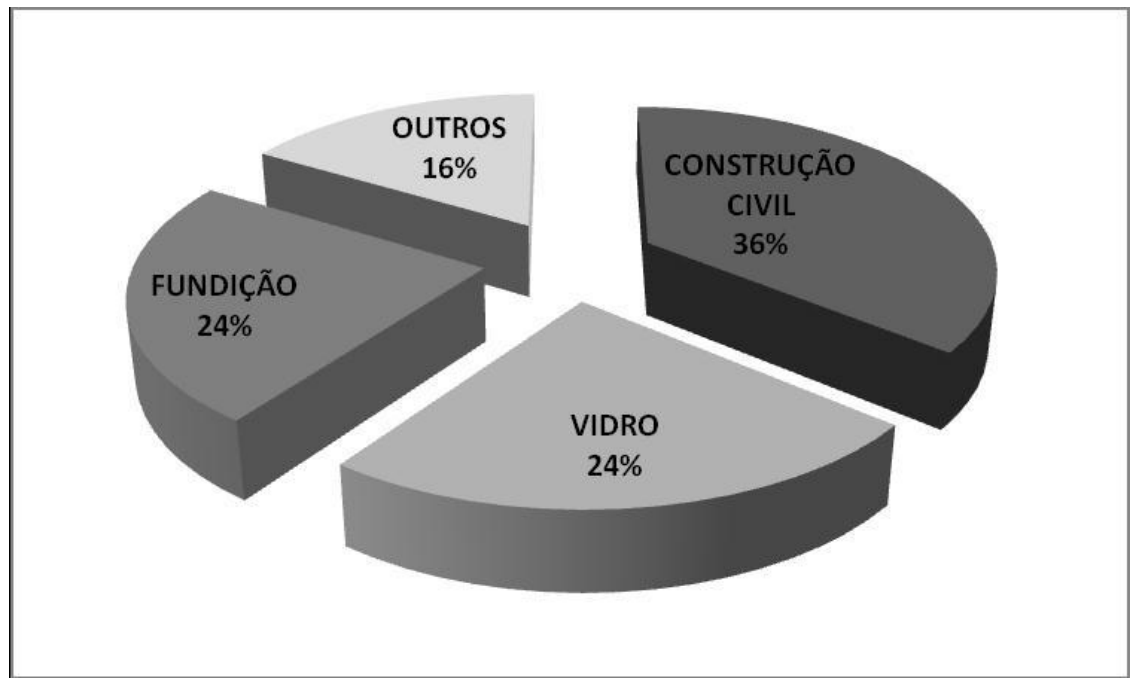

Fonte: Departamento Nacional da Produção Mineral (2010)

Figura 6 - Distribuição da demanda de areia industrial - principais segmentos de consumo - ano base 2009

Observou-se que o consumo de areia industrial tornou-se crescente, desde meados de 2009, em função, principalmente, da demanda derivada da indústria automobilística (fundição e vidros planos) e da indústria de construção (argamassa, cerâmicas e vidros).

A demanda no País concentra-se na região Sudeste, notadamente no Estado de São Paulo, em decorrência da sua grande concentração industrial e populacional, cujo mercado corresponde mais de $50 \%$ do consumo brasileiro (DNPM, 2010). Investimentos em empreendimentos vidreiros e siderúrgicos no Rio Grande do Sul e em Santa Catarina impulsionaram a demanda na região Sul, Já a expansão da cadeia produtiva da construção civil está motivando o crescimento nas regiões Nordeste e Centro-Oeste. 


\subsection{Reservas}

Segundo dados do DNPM, as reservas medidas de areia industrial em todo o País superam 2,5 bilhões de toneladas (Figura 7), concentrando-se principalmente nas regiões Sudeste e Sul, onde estão localizadas as maiores jazidas e minas em operação.

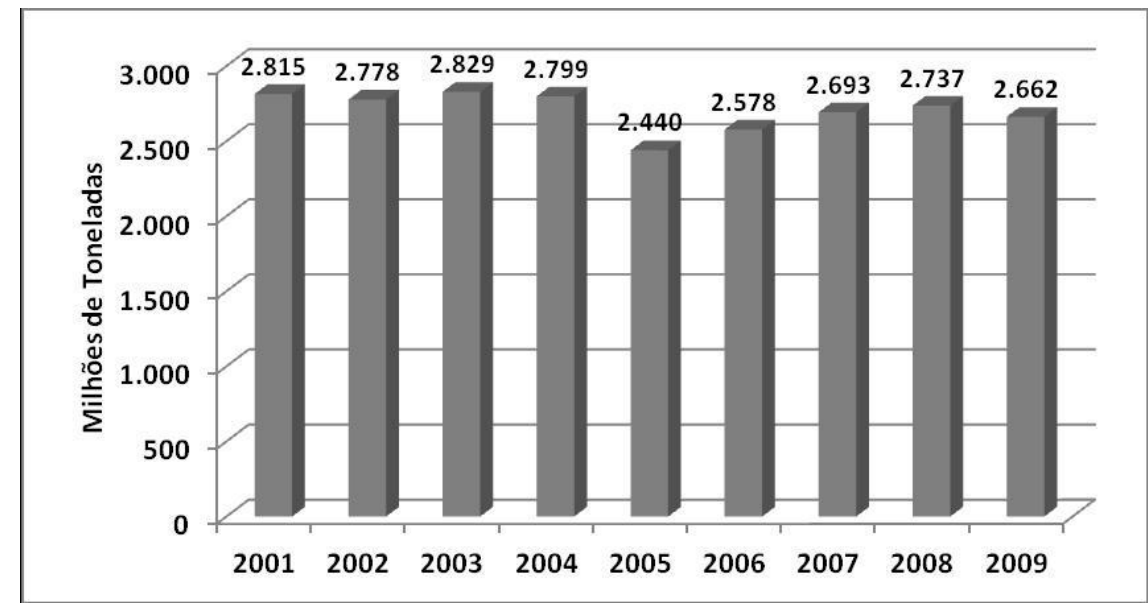

Fonte: Departamento Nacional da Produção Mineral (2002 a 2010)

Figura 7 - Evolução das reservas medidas de areia industrial - 2001 a 2009

Os dados da Figura 8 correspondem às reservas dos 10 estados com maior dotação de areia industrial.

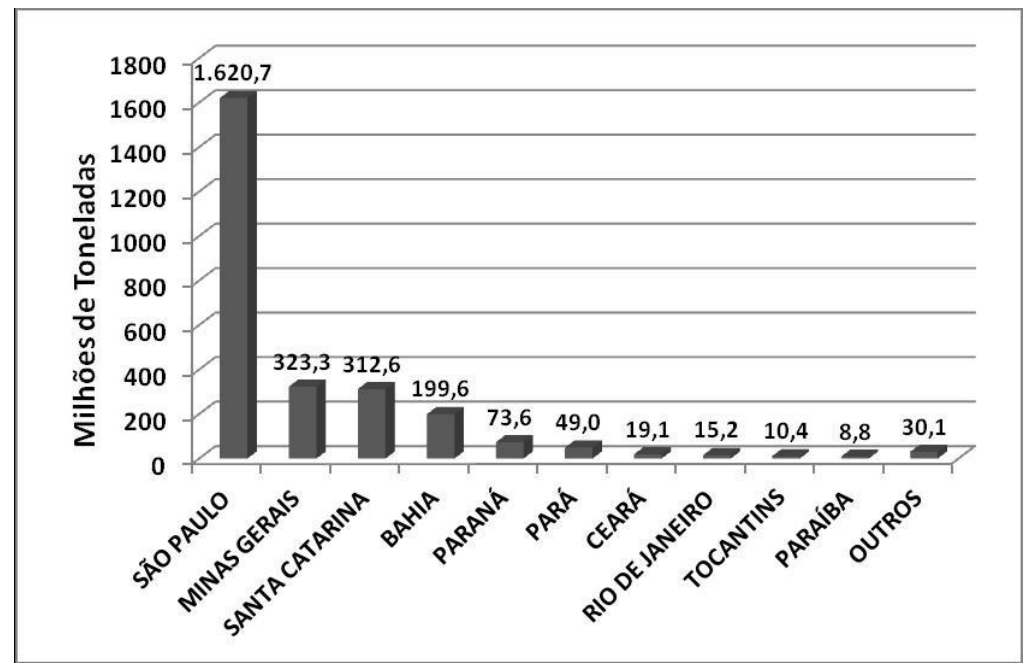

Fonte: Departamento Nacional da Produção Mineral (2002 a 2010)

Figura 8 - Distribuição das reservas de areia industrial no Brasil por unidades da federação

Outros estados detentores de jazidas expressivas são Minas Gerais, Santa Catarina, Bahia, Paraná e Pará, que juntos totalizam 36\% das reservas nacionais.

$\mathrm{Na}$ Tabela 4 relacionam-se os municípios que detém as maiores reservas, subdivididas em areia industrial (materiais sedimentares quartzosos friáveis) e quartzito industrial (rochas quartzosas que necessitam de cominuição para o uso). 
Tabela 4: Municípios detentores das principais reservas de areia industrial

\begin{tabular}{lcc}
\hline \multicolumn{3}{c}{ AREIA INDUSTRIAL } \\
\hline \multicolumn{1}{c}{ MUNICíPIO } & UF & $\begin{array}{c}\text { RESERVA } \\
\text { (toneladas) }\end{array}$ \\
\hline Itirapina & SP & 276.412 .960 \\
\hline Descalvado & SP & 172.816 .866 \\
\hline Bofete & SP & 162.563 .539 \\
\hline Analândia & SP & 146.566 .084 \\
\hline Peruíbe & SP & 87.375 .255 \\
\hline Araguari & SC & 86.247 .223 \\
\hline Bal. Barra do Sul & SC & 69.978 .071 \\
\hline S. Francisco do Sul & SC & 53.826 .252 \\
\hline Imbituba & SC & 45.307 .708 \\
\hline Breu Branco & PA & 30.448 .326 \\
\hline & QUARTZO INDUSTRIAL \\
\hline Fonte: Departamento Nacional da Produção Mineral \\
\hline \multicolumn{1}{c}{ MUNICÍPIO } & UF & RESERVA \\
\hline (toneladas)
\end{tabular}

A análise dos dados relacionados na Tabela 4 mostra que a maior parte das reservas de areia industrial (60\%) situa-se no interior paulista, nos municípios de Descalvado, Analândia, Bofete e Itirapina. Os municípios de Santa Catarina com maiores reservas são, respectivamente, Araguari e Balneário Barra do Sul. Os municípios paulistas de Jundiaí e Itapeva possuem as maiores reservas de quartzito industrial. Campo Largo no Paraná e vários municípios de Minas Gerais também possuem reservas consideráveis deste bem mineral.

\subsection{Estimativas de produção futura}

A projeção da produção de areia industrial no País entre 2010 e 2030 foi estimada considerando a evolução da quantidade produzida diante da variação do Produto Interno Bruto (PIB) de minerais não metálicos. Partindo-se dos três cenários relacionados na Tabela 2 e da produção de total areia industrial de 2009 na Figura 2 (5,8 milhões de toneladas), foi possível estimar a produção deste bem mineral de 2010 até 2030 como mostra a Tabela 5. 
Tabela 5: Projeção da produção de areia industrial no período 2012 a 2030

\begin{tabular}{|c|c|c|c|}
\hline \multirow[t]{4}{*}{ Ano } & \multicolumn{3}{|c|}{ Produção Estimada de Areia Industrial (Mt) } \\
\hline & \multicolumn{3}{|c|}{ Cenários } \\
\hline & Frágil & Vigoroso & Inovador \\
\hline & PIB $-8,2 \%$ a $a$. & PIB - 9,1\% a.a. & PIB $-10,0 \%$ a.a. \\
\hline 2010 & 6,2 & 6,3 & 6,4 \\
\hline 2012 & 7,3 & 7,5 & 7,7 \\
\hline 2016 & 10,0 & 10,6 & 11,3 \\
\hline 2020 & 13,6 & 15,0 & 16,5 \\
\hline 2024 & 18,7 & 21,2 & 24,1 \\
\hline 2028 & 25,6 & 30,1 & 35,3 \\
\hline 2030 & 29,9 & 35,8 & 42,7 \\
\hline
\end{tabular}

Fonte: elaborado pelos autores.

Por meio da análise dos dados relacionados na Tabela 5, pode-se estimar que a produção de areia industrial se situará na faixa entre 13,6 e 16,5 Mt em 2020 e entre 20,9 e 42,7 Mt em 2030. Trata-se de valores expressivos, sobretudo se a tendência da demanda acompanhar o cenário mais dinâmico da economia.

Tomando-se como referência o cenário frágil (mais conservador), em que a produção estimada deverá superar $10 \mathrm{Mt} / \mathrm{ano}$ a partir de 2016, os expressivos depósitos já dimensionados (2,7 bilhões de toneladas em 2009 - Figura 7), não terão dificuldades para suprir o acréscimo da demanda no País por muitas décadas. Isso sem considerar que novos investimentos em pesquisas geológicas estão em andamento pela Unimin, Saint Gobain e Mineração Descalvado com a finalidade de descobrir novas jazidas. Novos depósitos de areia para argamassa também são avaliados nos estados do Rio de Janeiro, Espírito Santo, Mato Grosso, Bahia, Pará e Amazonas, indicando que há uma grande potencialidade de oferta em várias regiões do País.

Apesar da elevada dotação mineral, fatores que podem interferir nesse cenário de abundância de reservas referem-se principalmente à crescente concorrência pela ocupação dos espaços territoriais, envolvendo, especialmente, a demanda em expansão pelo uso dos recursos hídricos, o avanço das áreas urbanas e industriais, além da importante tendência de garantia de maiores áreas dedicadas à preservação ambiental.

\subsection{Tecnologia da mineração de areia industrial}

As areias industriais são lavradas por diferentes métodos a depender do tipo de depósito. No caso da areia não consolidada, coberta por uma lâmina d'água, a lavra é feita por draga flutuante que remove a areia e a envia para uma pilha de secagem. Quando o material arenoso submerso está entremeado a lentes argilosas, a lavra pode ser feita com draglines, com custos operacionais e de manutenção mais elevados comparativamente aos da draga flutuante (ZDUNCZYK; LINKOUS, 1994). Em algumas minerações no Sul do Brasil, a lavra é feita a céu 
aberto, em bancadas, com a extração da areia por retroescavadeiras, seguido de transporte, por caminhões basculantes, para a usina de beneficiamento (FERREIRA; DAITX, 2003). Nas regiões produtoras do estado de São Paulo as areias industriais são lavradas de diferentes formas, sendo que dominam as lavras em cava (FERREIRA; DAITX, 1997).

No que se refere ao beneficiamento da areia industrial, este é variável em complexidade, dependendo das especificações requeridas. $O$ processamento típico consiste em: lavagem e classificação; atrição e peneiramento (FERREIRA; DAITX, 2003a; BRITISH GEOLOGICAL SURVEY, 2004). A lavagem e a classificação por hidrociclones visam a remoção da fração granulométrica mais fina (geralmente síltico-argilosa), prejudicial ao processo de produção de vidros especiais ou moldes de fundição pelo fato de conter alumínio, ferro e álcalis. A atrição consiste em um processo de agitação intensa da polpa, que provoca a remoção da fração fina, agregada à superfície das partículas maiores. Esse processo de agitação promove a eficiência da separação das frações fina e grossa e, como consequência,a obtenção de um material mais puro por meio de peneiramento ou hidrociclonagem. O peneiramento, por sua vez, consiste na separação por tamanho, separando as frações grossas e finas, para a obtenção de um material com a distribuição granulométrica desejada. Outros processos podem ser utilizados de maneira complementar, como a flotação, em Analândia, e a separação magnética, em Descalvado, buscando reduzir o teor de ferro de parte da areia destinada à fabricação de vidro. A flotação e a separação magnética têm por finalidade a purificação ou remoção de impurezas da areia em muitas situações.

Um desafio enfrentado pelas pequenas e médias empresas de mineração é suprir o volume requerido e atender as especificações técnicas das indústrias de cerâmica, química, argamassa e de cimento, entre outras. Isso requer investimentos em equipamentos, tecnologia e na qualificação profissional (áreas técnica e gerencial), os quais nem sempre estão ao alcance desses mineradores, impulsionando uma maior concentração no setor.

Como também acontece com outros segmentos da indústria mineral, além da necessidade de modernização tecnológica por parte do setor produtivo, a disputa crescente pelo espaço territorial por diferentes formas de uso e ocupação, e as limitações ambientais à implantação de atividades econômicas no país (leis restritivas, criação de unidades conservação) determinam importante papel ao poder público na garantia da disponibilidade das reservas minerais. Como salientado pelo Cabral Júnior et al. (2008), para tanto, é imperativo a inclusão da mineração nos instrumentos públicos de planejamento e gestão, de modo a compatibilizar o desenvolvimento da atividade mineral com outras vocações econômicas do território e com a preservação ambiental. Isto pode ser obtido, à medida que se efetue um planejamento adequado, fundamentado na integração de conhecimentos abrangendo o meio físico, biótico e das vocações naturais do território, e que pode ser institucionalizado nos instrumentos de ordenamento territorial, caso, por exemplo, dos planos diretores municipais.

\subsection{Aspectos ambientais}

Os métodos de lavra mais usuais de areia industrial com draga flutuante geram impactos ambientais, por vezes significativos. A Secretaria Estadual do Meio Ambiente do Estado de São Paulo determinou uma série de procedimentos de recuperação dessas áreas, com resultados importantes (ALMEIDA e SANCHEZ, 2005). Mas esses autores advertem que, nem sempre há um acompanhamento e fiscalização sistemática dos projetos de recuperação. 
Nas minas de areia industrial do interior paulista, o material estéril superficial é constituído de solo com espessura entre 0,2 e 1,0 m. Esse material é removido com pá carregadeira e disposto em local adequado para posterior utilização, quando da reabilitação da área minerada. No caso da mina da Saint-Gobain em Bofete, o retorno do capeamento do solo se dá sobre o piso da mina nos painéis de lavra minerados e já assoreados com lama argilosa. A etapa seguinte consiste em recuperar a vegetação via reflorestamento com eucalipto e espécies nativas. Na mina de Bofete, da Saint Gobain, faz-se também reflorestamento com eucaliptos. É necessário ponderar, entretanto, que a utilização de eucalipto para o reflorestamento pode trazer consequências negativas para o nível do lençol freático das áreas no entorno, além de não prover benefícios para a fauna.

Na área explorada pela Mineração Jundu em Descalvado, a argila, correspondendo $6 \%$ do material lavrado, é removida e disposta em lagoas de sedimentação. Estas lagoas, após assoreamento total e adensamento da argila decantada, são recapeadas com solo, seguida de recuperação da paisagem via plantio de espécies nativas. As lagoas de sedimentação, entretanto, podem não oferecer as condições ideais para o desenvolvimento de algumas espécies, devido à alta compactação e baixa porosidade, provocando uma mortandade de até $38 \%$ das mudas, contra $10 \%$ tido como valor de referência (ALMEIDA e SANCHEZ, 2005).

$\mathrm{Na}$ Mineração Descalvado o capeamento superficial tem espessura média de 0,5 m e é composto por material orgânico. Como não há possibilidade de aproveitamento econômico para fins industriais, é utilizado na recuperação ambiental na atividade de reflorestamento. $O$ passivo ambiental da Mineração, que é constituído pelas áreas degradadas pela lavra, é habitualmente recuperado. Neste sentido, existem planos de recuperação de áreas degradadas realizados, em andamento e previstos. Os mais antigos datam de meados dos anos 1990. Áreas lavradas foram recuperadas e monitoradas, restaurando-se o ecossistema, com o reflorestamento das áreas com mudas de espécies nativas.

Como prática de recuperação ambiental, a Mineração Descalvado replanta numa área de 18 hectares cerca de 3.000 mudas/ano envolvendo em média 100 diferentes espécies nativas da região. A empresa foi a primeira do segmento a obter a certificação pela ISO 14.001. A mina e unidade de beneficiamento de Bofete da Saint Gobain também são certificadas por esta norma.

\section{CONSIDERAÇÕES FINAIS}

Em relação à estrutura de mercado, pode-se observar que há uma tendência à concentração empresarial do setor produtivo de areia industrial, com a aquisição das pequenas minerações pelas grandes empresas. Isto decorre das poucas possibilidades de expansão dos pequenos empreendimentos, seja pelas condições naturais de suas jazidas ou pela dificuldade de atenderem às exigências dos produtores de areia para vidro, fundição, cerâmica, argamassa e concreto, e o cumprimento das crescentes determinações de controle ambiental nos processos de lavra e beneficiamento do minério. Há uma tendência de deslocamento das atividades de mineração para regiões mais próximas dos centros consumidores, isso reduz os custos de transporte e, ao mesmo tempo, evita a proximidade com unidades de conservação ambiental.

Além da responsabilidade de modernização do próprio setor produtivo, o desenvolvimento em bases sustentáveis da mineração de areia industrial vincula-se a ação do Estado, notadamente, no que assegura a disponibilidade das reservas minerais, por meio da 
inserção da mineração nos instrumentos de ordenamento territorial. Mesmo considerando que as reservas medidas são bastante expressivas em algumas regiões do País, há que se ter em perspectiva o planejamento do uso e ocupação do solo para que a mineração de areia industrial não venha a conflitar com outras atividades futuramente.

Finalmente, cabe destacar que, a pesquisa insere algumas limitações pertinentes aos dados quantitativos avaliados que precisam ser destacados. As estatísticas oficiais mais recentes disponíveis são de 2010 e dizem respeito apenas às quantidades e valores de produção comercializada, respectivamente, em 2009. Essas estatísticas, aqui discutidas, para areia industrial englobam também areia para argamassa usada na construção civil, quartzito industrial, quartzo e sílex, devido a alterações na forma de agregação de dados de produção pelo DNPM.

A inexistência de estatísticas sobre consumo de areia industrial gera a necessidade de assumir como dados de consumo os de produção beneficiada, disponíveis no Anuário Mineral Brasileiro, mesmo sabendo que certa quantia da produção beneficiada de um ano pode ter sido transferida como estoque para o seguinte, e que os dados sobre areias importadas também não são considerados, mesmo sendo eles pouco significativos em termos de participação porcentual no consumo.

Outra limitação refere-se à adoção de indicadores de crescimento do PIB para a indústria de minerais não metálicos, obtidos com base em valores mínimos e intermediários de série histórica anterior (1990 - 2008), para se estimar a produção futura (de 2010 até 2030) para areia industrial poderá não refletir a realidade futura deste segmento da indústria mineral. Segundo Veloza (2009), o comportamento do mercado consumidor deste bem mineral nos próximos anos dependerá muito de variáveis macroeconômicas, uma vez que os segmentos consumidores possuem crescimento interligado com setores produtivos diversos, quais sejam: construção civil, siderúrgico / metalúrgico e vidreiro, dentre outros.

\section{REFERÊNCIAS}

ALMEIDA, R. O. P. O.; SANCHEZ, L. E. Revegetação de áreas de mineração: critérios de monitoramento e avaliação do desempenho. Revista Árvore, 29, n. 1, 2005. 47-54.

APPOLINÁRIO, F. Dicionário da Metodologia Científica: um guia para a produção do conhecimento científico. São Paulo: Editora Atlas S.A., 2004.

AZEVEDO, P. B. M.; RUIZ, M. S.. Perfil 3 - Areia, quartzo e quartzito industrial. Mercado produtor mineral do Estado de São Paulo: levantamento e análise. São Paulo: Instituto de Pesquisas Tecnológicas, 1990, pp.49-59. (Publicação IPT, n. 1822).

BRITISH GEOLOGICAL SURVEY. Mineral Planning Factsheet: Silica Sand. Nottingham: BGS, 2004. 9 p. Disponível em: <http://www.bgs.ac.uk/mineralsuk/home.html>. Acesso em: 12 jun. 2009

CABRAL JÚNIOR, M. et al. A mineração no Estado de São Paulo: situação atual, perspectivas e desafios para o aproveitamento dos recursos minerais. Geociências, v. 27, p. 171-192, 2008.

CHAVES, A. P.; WHITAKER, W. Operações de beneficiamento de areia. In: ALMEIDA, S. L. M.; DA LUZ, A. B. (Org.). Manual de agregados para construção civil. Rio de Janeiro: CETEM/MCT, 2010, v. , p. 129-158. 
COELHO, J. M. Produto 44 Areia Industrial - Contrato № 48000.003155/2007-17: Desenvolvimento de Estudos para Elaboração do Plano Duodecenal (2010 - 2030) de Geologia, Mineração e Transformação Mineral. Belo Horizonte: J. Mendo Consultoria, 2010. 56 p. (Relatório Técnico 44).

COOPER, D. R.; SCHINDLER, P. S. Métodos de pesquisa em administração. 7ạ. ed. Porto Alegre: Bookman, 2003.

DEPARTAMENTO NACIONAL DA PRODUÇÃO MINERAL. Anuário Mineral Brasileiro. Brasília: DNPM, 2002 - 2010.

DIAS, E. G. C. Mercado consumidor mineral. IPT/ Pró-Minério, São Paulo, 1981.

DIAZ, R. J.; CUTTER, J. . G. R.; HOBBS, I. C. H. Potential impacts of sand mining offshore of Maryland and Delaware: Part 2 - biological considerations, West Palm Beach, 20, n. 1, 2004. 6169.

FERREIRA, G. C. Avaliação da evolução dos mercados produtores e consumidor de areia industrial no Estado de São Paulo. Geociências, São Paulo, v.17, n.2, p.433-466, 1997.

FERREIRA, G. C.; DAITX, E. C. A áreas produtoras de areia industrial no Estado de São Paulo. Revista Escola de Minas, Ouro Preto, v.50, n.4, p.54-60, out./dez. 1997.

FERREIRA, G. C. e DAITX, E. C. Características e especificações da areia industrial. Geociências, UNESP, São Paulo, vol.19, n.2, p.235-242. 2000.

FERREIRA, G. C.; DAITX, E. C. A mineração produtora de areia industrial na região Sul do Brasil. Revista Escola de Minas, Ouro Preto, v.56, n.1, p.59-65, jan./mar. 2003a.

FERREIRA, G. C.; DAITX, E. C. Mercado produtor de areia industrial nos estados de São Paulo, Santa Catarina, Paraná e Rio Grande do Sul. Geociências, São Paulo, v.22, n. especial, p.41-47, 2003b.

HOBBS, C. H. . I. An investigation of potential consequences of marine mining in shallow water: an example from the mid-Atlantic coast of the United States. Journal of Coastal Research, West Palm Beach, 18, n. 1, 2002. 94-101.

HOBBS, C. H. I. Considerations in marine sand mining and beach nourishment. 2007 OCEANS. Vancouver: MTS - IEEE. 2007. p. 33-42.

LUZ A. B.; LINS, F. A. F. Rochas \& Minerais Industriais: Parte II: Rochas e minerais industriais: usos e especificações. 5. areia industrial. Rio de Janeiro: CETEM / MCT, 2005. 726p.

MAA, J. P. Y.; HOBBS, C. H.; HARDAWAY JUNIOR, C. S. A criterion for determining the impact on shorelines caused by altering wave transformation. Journal of Coastal Research, West Palm Beach, 17, n. 1, 2001. 107-113.

NAVA, N. Pesquisa geológica e utilização industrial. Mineração e Metalurgia, v.50, n.477, jun. 1986.

NOGUEIRA, D. O. Areia industrial. Saint Gobain, Divisão Weber-Quartzolit, Jandira. Entrevista concedida a autores, em 22 jun. 2009.

SEVERINO, A. J. Metodologia do trabalho científico. 23ạ. ed. São Paulo: Cortez, 2007. 
SHREVE, R. N.; BRINK JUNIOR, J. A. Indústrias de vidro. Indústria de processos químicos. 4. Ed., Rio de Janeiro: Editora Guanabara, 1977. p.160-175.

U.S. GEOLOGICAL SURVEY. Mineral Commodity Summaries, Jan. 2009.

<http://minerals.usgs.gov/minerals/pubs/commodity/silica/mcs-2009-sandi.pdf>. Acesso em: 21 maio 2009.

VELOSA, L. M. M. Areia Industrial. Mineração Descalvado, Descalvado, 04 ago. 2009. Entrevista concedida a autores. 